\title{
APLIKASI TEKNOLOGI INFORMASI BERBASIS SLiMS DI PERPUSTAKAAN UIN SULTHAN THAHA SAIFUDDIN JAMBI
}

\author{
RUDIANTO \\ antorudi315@yahoo.com
}

Pascasarjana Sekolah Tinggi Ilmu Komputer Dinamika Bangsa Jambi

\begin{abstract}
The rapid development of technology requires every library to improve services continuosly in various aspects. The improvement of Information technology becomes an absolute must tried to achieve the goal of a library. Implementation of automation in library is a process of application done in the library from manual way to digitalization which aims to facilitate librarians in every activity and also facilitate them in tracking information. The implementation of library automation is covered in several areas: cataloging, circulation, OPAC establishment, information alert services, and the procurement of books and magazines. Every services has been automated into one application called SLiMS except the procurement of books and magazines as well as information alert service is still by manual. The causes are constrained to infrastructure, human resources, the systems used are omgood and law of budget. The efforts they undertake, among others, are the submission of letters rectorate request in addition of tools, the asking addition of human resources, and enlarging of the budget.
\end{abstract}

Key Words: SLiMS, Perpustakaan, automasi

\section{A. PENDAHULUAN}

Perkembangan dunia perpustakaan dilihat dari segi koleksi data dan dokumen yang disimpan, diawali dari perpustakaan tradisional yang hanya terdiri dari kumpulan koleksi buku tanpa katalog, kemudian muncul perpustakaan semi modern yang menggunakan katalog (index). Perkembangan mutakhir adalah munculnya perpustakaan digital (digital library) yang memiliki keunggulan dalam kecepatan pengaksesan karena berorientasi ke data digital dan media jaringan komputer (internet). Selain itu dari segi manajemen (teknik pengelolaan) dengan semakin kompleksnya koleksi perpustakaan, saat ini muncul kebutuhan akan penggunaan teknologi informasi untuk otomatisasi business process $\mathrm{di}$ perpustakaan. Sistem yang dikembangkan kemudian terkenal dengan sebutan sistem otomasi perpustakaan (library automation system). ${ }^{1}$

\footnotetext{
${ }^{1}$ Romi Satria WahonoTeknologi Informasi untuk Perpustakaan Digital dan Sistem Automasi Perpustakaan. (2006, September 27) Ilmu computer.com. Diakses pada tanggal 25 November 2014
} 
Salah satu hal yang sangat penting bagi sebuah perpustakaan khususnya perpustakaan perguruan tinggi adalah koleksi namun disamping itu yang lebih penting lagi adalah bagaimana cara kita memperoleh koleksi itu dengan cepat, tepat dan akurat tanpa harus membuang banyak waktu dan agar informsi yang kita dapatkan sesuai dengan keinginan, salah satunya adalah dengan menerapkan sistem automasi di perpustakaan. Adanya penerapan teknologi informasi saat ini, sudah menjadi ukuran untuk mengetahui tingkat kemajuan dari perpustakaan tersebut, bukan lagi pada besarnya gedung yang dipakai, banyaknya rak buku, ataupun banyak pengguna.Semakin canggih kinerja perpustakaan semakin maju perpustakaan tersebut, dengan demikian paradigma lama tentang perpustakaan dengan berbagai kerumitannya dalam melakukan pengelolaan pustaka, keanggotaan serta sirkulasi koleksi kini terhapus. Semua dapat dilakukan dengan perubahan tata cara pengelolaan perpustakaan yang memanfaatkan teknologi informasi. $^{2}$

Teknologi yang semakin canggih pun membuat informasi semakin cepat, mudah untuk diakses serta mempermudah kerja manusia dan melaksanakan setiap aktivitasnya. Setiap hari, jam, menit bahkan detik terjadi perubahan informasi yang berkembang dengan sangat pesat dan menjadi kebutuhan bagi sebagian besar orang, terutama bagi kaum akademis seperti mahasiswa, dosen serta para peneliti. Untuk dapat meningkatkan layanan kepada para penggunanya. Maka perpustakaan dituntut juga untuk dapat menggunakan teknologi informasi. Dengan harapan dapat menciptakan perpustakaan yang mampu memenuhi kebutuhan para pengguna atau pemustaka akan informasi yang diinginkan secara cepat, tepat dan juga membantu kerja para pustakawan serta seluruh staf yang ada di perpustakaan dalam mengolah hingga menyediakan layanan yang baik kepada para pengguna.

Keberadaan teknologi informasi berperan penting terhadap lahirnya berbagai macam bentuk informasi, dalam hal ini perpustakaan memiliki posisi yang sangat penting yaitu sebagai penyedia, pengelola serta penyebarluasan informasi kepada masyarakat. Kini pustakawan tidak hanya menunggu

\footnotetext{
${ }^{2}$ Wahyu Supriyanto. Teknologi Informasi Perpustakaan. (Yogyakarta: Kanisius, 2008) hlm. 1718.
} 
pengunjung datang ke perpustakaan melainkan harus lebih pro aktif menawarkan jasa pelayanan informasi tentunya dengan bantuan teknologi informasi berupa perangkat komputer dan aplikasinya yang menghadirkan beberapa kemudahan baik bagi pustakawan maupun bagi pemustakanya. Aplikasi komputer terintegrasi dengan layanan di perpustakaan yang selanjutnya diterapkan pada semua bidang, sehingga pekerjaan perpustakaan dapat menjadi inti yang mendasari dimulainya sistem layanan terautomasi.

Perkembangan teknologi informasi yang sedemikian pesat memberikan dampak besar terhadap hampir semua bidang kehidupan tak terkecuali perpustakaan. Perpustakaan berlomba-lomba menerapkan teknologi informasi untuk memberikan pelayanan lebih baik kepada pemustakanya. Setidaknya alasan yang melatarbelakangi pengaplikasian teknologi informasi di perpustakaan, yaitu mengatur informasi ing-griya (in-house information) serta mengusahakannya agar informasi tersebut dapat ditemubalikkan, bertambahnya beban kerja karena jumlah dokumen yang diolah semakin besar ataupun akses terhadap dokumen semakin meningkat, perlunya efisiensi yang lebih besar dan perlunya menghemat waktu dan tenaga staf sehingga dapat menekan ongkos operasional, komputerisasi merupakan jalan untuk meningkatkan jasa, membentuk jaringan kerja sama perpustakaan. $^{3}$

Pengembangan teknologi informasi di perpustakaan sebenarnya merupakan wujud dari berbagai kepentingan. Kepentingan ini mendorong perpustakaan untuk melakukan modernisasi pelayanan dan menerapkan teknologi informasi dalam aktifitas kesehariannya. ${ }^{4}$ Setiap Perpustakaan pada zaman sekarang harusnya telah mengembangkan perpustakaan dari yang berbentuk manual menjadi terautomasi dengan menerapkan teknologi informasi. Adapun salah satu software yang bisa diterapkan di perpustakaan yaitu SLiMS. Untuk saat ini beberapa perpustakaan di perguruan tinggi telah memanfaatkan Senayan Library Management System (SLiMS). Alasan memilih menerapkan SLiMS atau Senayan Library Management System sebagai software otomasi perpustakaan

\footnotetext{
${ }^{3}$ Sulistyo Basuki. Pengantar Ilmu Perpustakaan. (Jakarta: Gramedia, 1993) hlm. 91

4 Arif Surachman. Layanan Perpustakaan Berbasis Teknologi Informasi. diakses pada 25 November 2014
} 
dikarenakan SLiMS lebih familiar di kalangan perpustakaan. Tujuan diterapkannya aplikasi SLiMS di perpustakaan adalah untuk mempermudah pelayanan dan untuk memberikan pelayanan yang prima kepada pemustaka.

\section{B. Kajian Teori}

\section{Teknologi Informasi}

\section{a. Pengertian Teknologi Informasi}

Teknologi informasi (information technology) biasa disebut TI, IT, atau infotech. Berbagai definisi tentang informasi diberikan pada tabel berikut dengan maksud dapat memberikan gambaran lebih lanjut tentang teknologi informasi. ${ }^{5}$

Tabel 2.1 Pengertian Teknologi Menurut Para Ahli

\begin{tabular}{|l|l|}
\hline \multicolumn{1}{|c|}{ Sumber } & \multicolumn{1}{|c|}{ Definisi } \\
\hline Haag dan Keen (1996) & $\begin{array}{l}\text { Teknologi informasi adalah seperangkat alat yang } \\
\text { membantu anda bekerja dengan informasi dan } \\
\text { melakukan tugas-tugas yang berhubungan dengan } \\
\text { pemrosesan informasi. }\end{array}$ \\
\hline Martin (1999) & $\begin{array}{l}\text { Teknologi informasi tidak hanya terbatas pada } \\
\text { teknologi komputer (perangkat keras dan } \\
\text { perangkat lunak) yang digunakan untuk } \\
\text { memproses dan menyimpan informasi, melainkan } \\
\text { juga mencakup teknologi komunikasi untuk } \\
\text { mengirimkan informasi }\end{array}$ \\
\hline Williams dan Sawyer \\
(2003) & $\begin{array}{l}\text { Teknologi informasi adalah teknologi yang } \\
\text { menggabungkan komputasi (computer) dengan } \\
\text { jalur komunikasi berkecepatan tinggi yang } \\
\text { membawa data, suara, dan video. }\end{array}$ \\
\hline
\end{tabular}

Teknologi atas dua teknologi yang mendasari teknologi informasi adalah sebagai berikut:

5 Abdul Kadir \& Terra CH. Triwahyuni Pengenalan Teknologi Informasi. (Yogyakarta: Andi, 2005) hlm. 2 


\section{1) Teknologi Komputer}

Teknologi komputer adalah teknologi yang berhubungan dengan komputer, termasuk peralatan-peralatan yang berhubungan dengan komputer seperti printer, pembaca sidik jari, dan bahkan CD-ROM. Komputer adalah mesin serbaguna yang dapat dikontrol oleh program, digunakan untuk mengolah data menjadi informasi. Program adalah deretan instruksi yang digunakan untuk mengendalikan komputer sehingga komputer dapat melakukan tindakan sesuai yang dikehendaki pembuatnya. Data adalah bahan mentah bagi komputer yang dapat berupa angka maupun gambar, sedangkan informasi adalah bentuk data yang telah diolah sehingga dapat menjadi bahan yang berguna untuk pengambilan keputusan. ${ }^{6}$

2) Teknologi komunikasi

Teknologi telekomunikasi atau biasa juga disebut teknologi komunikasi adalah teknologi yang berhubungan dengan komunikasi jarak jauh. Termasuk dalam kategori teknologi ini adalah telepon, radio dan televisi.

\section{b. Pengelompokan Teknologi Informasi}

Telah diketahui bahwa teknologi informasi mencakup teknologi komputer dan teknologi komunikasi. Lebih rinci, teknologi informasi dapat dikelompokkan menjadi 5 teknologi, yaitu:

1) Teknologi Masukan

Teknologi masukan (input technology) adalah perangkat keras komputer yang berfungsi sebagai alat untuk memasukkan data atau perintah ke dalam komputer. ${ }^{7}$ Contohnya keyboard dan mouse.

2) Mesin Pemroses

Mesin pemroses (processing mechine) lebih dikenal dengan sebutan CPU (Central Processing Unit), mikroprosesor, atau prosesor. CPU merupakan otak sistem komputer yang digunakan untuk mengolah instruksi

${ }^{6}$ Ibid., hlm. 3

${ }^{7}$ Edhy Sutanta. Pengantar Teknologi Informasi. (Yogyakarta: Graha Ilmu, 2005) hlm. 18 
program yang pada komputer ukuran mikro disebut sebagai micro processor. $^{8}$

\section{3) Teknologi Penyimpan}

Teknologi penyimpan dapat dibedakan menjadi dua kelompok, yakni memori internal dan penyimpan eksternal. Memori internal (biasa juga disebut main memori atau memori utama) berfungsi sebagai pengingat sementara baik bagi data, program, maupun informasi ketika proses pengolahannya dilaksanakan oleh CPU. Dua contoh memori internal yaitu ROM dan RAM. ROM (Read-Only-Memory) adalah memori yang hanya bisa dibaca, sedangkan RAM (Random Access Memory) adalah memori yang isinya bisa diperbaharui. Penyimpanan eksternal (external storage) dikenal juga dengan sebutan penyimpan sekunder. Penyimpanan eksternal adalah segala peranti yang berfungsi untuk menyimpan data secara permanen. ${ }^{8}$

4) Teknologi Keluaran

Teknologi keluaran (output technology) adalah teknologi yang berfungsi untuk menampilkan/mencetak keluaran sebagai hasil pengolahan data. $^{9}$ Layar atau monitor dan printer merupakan peranti yang biasa digunakan sebagai peranti keluaran.

5) Teknologi Perangkat Lunak

Perangkat lunak (software) atau dikenal juga dengan sebutan program adalah deretan instruksi yang digunakan mengendalikan komputer sehingga komputer dapat melakukan tindakan sesuai yang dikehendaki pembuatnya. Tentu saja untuk mengerjakan tugas yang berbeda diperlukan pula perangkat lunak tersendiri. Sebagai contoh, Microsoft Word merupakan contoh perangkat lunak pengolah kata, yaitu perangkat lunak yang berguna untuk membuat dokumen, sedangkan Adobe Photoshop adalah perangkat lunak yang berguna untuk mengolah gambar. ${ }^{\mathbf{1 0}}$

\footnotetext{
${ }^{8}$ Ibid., hlm. 7

${ }^{8}$ Abdul Kadir \& Terra CH. Triwahyuni. Op. Cit., hlm. 7

${ }^{9}$ Edhy. Op. Cit., hlm. 19

${ }^{10}$ Abdul Kadir \& Terra CH. Triwahyuni. Op. Cit., hlm. 8
} 


\section{Pengertian dan Konsep SliMS}

Aplikasi SLiMS (Senayan Library Management System) atau yang lebih dikenal dengan nama "Senayan" adalah Aplikasi untuk manajemen administrasi dan konten di perpustakaan. Program ini bersifat Open Source Software (OSS) berbasis Web untuk memenuhi kebutuhan otomasi perpustakaan (library automation) skala kecil hingga skala besar. ${ }^{11}$

Senayan merupakan salah satu OSS berbasis web yang dapat digunakan sebagai perangkat lunak untuk membangun otomasi perpustakaan. Perangkat lunak berbasis web sesuai dengan kebutuhan perpustakaan karena aplikasi jenis ini memungkinkan perpustakaan mendekatkan berbagai produk layanannya dengan pengguna perpustakaan. Dengan jenis aplikasi ini pengguna dapat mengakses layanan perpustakaan tanpa harus datang ke perpustakaan melalui web atau portal perpustakaan. jika melihat sistem informasi atau berbagai perangkat lunak yang digunakan saat ini oleh perpustakaan di Tanah Air, banyak perpustakaan yang menggunakan perangkat lunak berbasis web.

Senayan dikembangkan dengan menggunakan berbagai perangkat lunak open source, web server, bahasa pemprograman dan database yang digunakan untuk mengembangkan Senayan semuanya merupakan perangkat lunak open source. Berbagai perangkat lunak yang digunakan untuk membangun Senayan antara lain Apache sebagai web server, PHP sebagai bahasa pemprograman dan MySQL sebagai database yang menyimpan transaksi data yang terjadi di Senayan. Perangkat lunak ini dibangun dengan menggunkan PHP sehingga kode sumber (source code) perangkat lunak ini bersifat terbuka. Kode sumber yang bersifat terbuka inilah yang memberikan peluang bagi pengguna untuk mengembangkan Senayan lebih lanjut sesuai dengan kebutuhan perpustakaan. Hal ini memungkinkan karena PHP merupakan bahasa pemprograman interpreter.

Senayan diproduksi dan dikembangkan oleh Pusat Informasi dan Humas Departemen Pendidikan Nasional. Lebih jelasnya lagi dipelopori oleh

\footnotetext{
11 Andres Amrullah. Pengalihan Data Bibliografi Perpustakaan Kebun Raya Bogor Dari "Winisis" menjadi "Senayan": Menuju Efisiensi dalam Pencarian Informasi. Visi Pustaka Vol. 14 No. 1, April 2012
} 
Hendro Wicaksono, Arie Nugraha dan Wardiyono. Sementara itu untuk dokumentasi dikerjakan oleh Purwoko, Sulfan Zayd, M. Rasyid Ridho, Arif Syamsudin. Selain itu juga ada Indra Sutriadi Pipii dan Eddy Subratha. Guna mendukung pengembangan Senayan kedepan, perangkat lunak otomasi perpustakaan ini memiliki komunitas pengembang yang tergabung dalam Senayan Developer Community (SDC).

Perangkat lunak otomasi perpustakaan memiliki fungsi untuk mempermudah kegiatan administrasi perpustakaan. Sebagai perangkat lunak otomasi perpustakaaan maka Senayan harus mampu mempermudah kegiatan administrasi perpustakaan. Jika melihat menu-menu yang disediakan Senayan, perangkat lunak ini mampu menjalankan fungsi administrasi yang ada di perpustakaan. Kegiatan pengolahan, peminjaman, pengembalian, pemesanan koleksi, penyiangan, manajemen anggota, fasilitas pencetakan barcode (barcode koleksi dan anggota) serta berbagai jenis laporan Senayan dapat membantu pihak manajemen untuk membuat kebijakan pangadaan atau sebagai bahan pertimbangan untuk memutuskan suatu kebijakan bagi perpustakaan. ${ }^{12}$ Semua kegiatan tersebut bisa dilakukan dengan menggunakan menu-menu atau fitur-fitur yang ada dalam Senayan.

\section{Metodologi}

Penelitian ini dilakukan dalam lingkup Perpustakaan UIN Sulthan Thaha Saifuddin Jambi dan terfokus pada bagian pelayanan sirkulasi yang sejauh ini telah menerapkan teknologi informasi untuk koleksi perpustakaan yang terotomasi dalam aplikasi Senayan Library Manajement System atau SLiMS dengan tujuan untuk melihat proses pemanfaatan dan efektivitas aplikasi teknologi informasi berbasis SLiMS. Key Informan dalam penelitian ini yaitu Kepala Perpustakaa UIN STS Jambi dan Informan dalam penelitian adalah pustakawan pada pelayanan sirkulasi dan pengelola aplikasi SLiMS di Perpustakaan UIN STS Jambi, kemudian Respondennya adalah pemustaka datang ke perpustakaan sebagai pengguna aplikasi SLiMS. Adapun sumber datanya berasal dari proses atau kegiatan yang berkaitan dengan layanan sirkulasi yang bersinggungan

\footnotetext{
${ }^{12}$ Dunia Perpustakaan. (20 Maret 2011). Sejarah Lengkap Software SLiMS (Senayan Library Management System). Diakses pada 26 November 2014.
} 
dengan penggunaan dan pemanfaatan aplikasi SliMS di Perpustakaan UIN STS Jambi. Metode pengumpulan data dalam penelitian ini adalah melalui observasi atau pengamatan secara langsung serta dokumentasi-dokumentasi yang diambil dan berkaitan dengan tulisan ini. Analisis data menggunakan metode komparatif atas hasil wawancara dengan informan, studi kepustakaan serta sekaligus membandingkan dengan hasil observasi. Untuk mempertinggi keabsahan dan langkah selanjutnya adalah analisis terhadap wawancara. Data yang diperoleh dari lapangan dilakukan analisis melalui tahap-tahap sebagai berikut: Kategorisasi dan mereduksi data, Data yang dikelompokkan selanjutnya disusun dalam bentuk narasi-narasi, sehingga berbentuk rangkaian informasi yang bermakna sesuai dengan masalah penelitian. Melakukan interpretasi data yaitu menginterpretasikan informasi terhadap masalah yang diteliti. Pengambilan kesimpulan berdasarkan susunan narasi yang telah disusun pada tahap ketiga, sehingga dapat memberi jawaban atas masalah penelitian. Melakukan verifikasi hasil analisis data dengan informan, yang berdasarkan pada kesimpulan tahap keempat.

\section{Pembahasan}

\section{Pemanfaatan Teknologi Informasi Senayan Library Management System} (SLiMS) untuk Mendukung Sistem Pelayanan Informasi pada Perpustakaan UIN Sulthan Thaha Saifuddin Jambi

Kehadiran perpustakaan sebagai pusat informasi dan sekaligus sebagai tempat pengembangan ilmu pengetahuan seperti yang dirasakan belakangan ini memiliki peran yang penting. Keberadaan perpustakaan semakin dirasakan penting oleh pemustaka yang haus akan informasi. Seiring berkembangnya teknologi, perpustakaan pun semakin berbenah diri.Sekarang perpustakaan berlomba-lomba untuk menerapkan sistem layanan yang terautomasi.Dalam membangun sistem otomasi dalam sebuah perpustakaan tentu saja banyak sekali pilihan software yang dapat digunakan, mulai dari yang bersifat open source atau gratis hingga yang berbayar.Software ini perpustakaan ciptakan untuk mendukung kemajuan dunia perpustakaan serta membantu dan memudahkan pustakawan dan pengelola perpustakaan dalam mengelola 
perpustakaan mulai dari sistem administrasi, pengolahan bahan pustaka hingga mempermudah dalam proses temu kembali informasi dalam perpustakaan.

Berdasarkan hasil temuan di lapangan menunjukkan bahwa teknologi informasi SLiMS untuk mendukung sistem pelayanan informasi pada Perpustakaan UIN STS Jambi yaitu:

\section{a. Pelayanan Sirkulasi}

\section{1) Kegiatan Peminjaman dan Pengembalian Koleksi}

Dalam era informasi dan teknologi serba canggih ini, perpustakaan juga ikut dalam perkembangan tersebut.Perkembangan teknologi informasi atau Information Technology (IT) telah membawa perubahan dalam berbagai sektor, termasuk dunia perpustakaan.pemanfaatan teknologi informasi dalam meningkakan kualitas layanan dan operasional telah membawa perubahan yang besar di perpustakaan. Perkembangan dari teknologi informasi dapat diukur dengan telah diterapkannya atau digunakannya berbagai sistem informasi menajemen perpustakaan merupakan pengintegrasian antara bidang layanan dengan perpustakaan.

Layanan sirkulasi merupakan salah satu kegiatan pokok di perpustakaan.Pelayanan dalam perpustakaan merupakan ujung tombaknya jasa perpustakaan, karena bagian inilah yang pertama kali berhubungan dengan pengguna perpustakaan.pelayanan sirkulasi ditujukan untuk memungkinkan pengguna memanfaatkan koleksi atau bahan pustaka dengan tepat guna, mengetahui koleksi, menjamin kembalinya bahan pustaka yang dipinjam. Pelayanan yang ramah dan sopan akan memberikan kesan yang baik dari pemustaka kepada perpustakaan. Pendukung pelayanan yang memuaskan merupakan dampak dari adanya pemanfaatan software untuk mendukung kecepatan dan ketepatan dalam pelayanan sirkulasi, penggunaan SLiMS meringankan tugas para pengelola perpustakaan baik itu staf dan juga pustakawan dalam pelayanan sirkulasi.

Dengan adanya aplikasi SLiMS ini, sangat membantu proses berlangsungnya sistem pelayanan informasi di sebuah perpustakaan seperti kegiatan peminjaman, pengembalian, penelusuran informasi akan menjadi lebih efektif dan efisien serta menghemat waktu baik itu dari pihak 
pengelola perpustakaan maupun pengguna atau pemustakanya. Melalui SLiMS ini, perpustakaan akan mengetahui buku-buku yang terlambat dikembalikan oleh pemustaka, denda keterlambatannya berapa. Jadi pengelola perpustakaan tidak perlu susah-susah lagi menghitung berapa hari keterlambatannya, karena di dalam SLiMS ini akan diketahui secara otomatis. Melalui SLiMS ini juga akan diketahui buku-buku yang sedang dipinjam sehingga pemustaka lain yang hendak meminjam buku yang sama tersebut tidak lagi mencari-cari buku yang hendak dipinjamnya tersebut di rak koleksi, dan masih banyak lagi kelebihan dari SLiMS ini.

Berdasarkan hasil observasi penulis, kegiatan layanan peminjaman dan pengembalian koleksi di perpustakaan UIN STS Jambi saat ini masih dilakukan secara manual. Pemustaka yang hendak meminjam buku datang menemui petugas untuk selanjutnya buku yang hendak dipinjam tersebut diberikan stempel peminjaman. Melihat hal tersebut, sangat disayangkan sekali bahwa aplikasi SliMS tidak dimanfaatkan untuk melakukan proses peminjaman dan pengembalian koleksi di Perpustakaan UIN STS Jambi. Karena aplikasi SLiMS tersebut memiliki fitur yang bisa melakukan kegiatan peminjaman dan pengembalian koleksi serta melihat berapa lama waktu koleksi telah dipinjamkan. Di samping itu juga, pustakawan mudah mengkoordinir koleksi-koleksi yang sedang dipinjam oleh anggota perpustakaan.

\section{2) Penelusuran Informasi dengan Menggunakan OPAC (Online Public}

\section{Access Catalog)}

OPAC yaitu sebuah fitur atau fasilitas yang dapat digunakan untuk memfasilitasi pengunjung untuk mencari koleksi, dengan menggunakan kata kunci judul, pengarang, subjek dan sebagainya.OPAC atau Online Public Access Catalog berfungsi sebagai alat telusur untuk menemukan informasi mengenai koleksi. Mengenai OPAC, pengguna dimungkinkan juga dapat mengetahui lokasi atau tempat penyimpanannya.

Perpustakaan sebagai salah satu penyedia informasi, dalam menyajikan informasi baik itu yang berupa buku maupun dokumentasi lainnya yang dimiliki menggunakan sarana temu kembali berupa katalog, 
bibiografi ataupun indeks.Informasi yang setiap saat bertambah ini dapat ditanggulangi dengan adanya sarana temu kembali informasi untuk menemukan kembali informasi-informasi yang relevan terhadap kebutuhan pengguna dari suatu kumpulan informasi secara otomatis.

Salah satu sarana temu kembali informasi adalah OPAC yang merupakan salah satu dari fitur SLiMS. SLiMS merupakan software yang digunakan oleh Perpustakaan UIN STS Jambi. Perpustakaan telah menyediakan sarana penelusuran informasi berupa OPAC (Online Public Access Catalogue) yang letaknya berada di dekat pintu masuk ruang sirkulasi.Dengan adanya sarana penelusuran OPAC ini, pemustaka dapat mencari atau menelusuri informasi mengenai koleksi yang mereka butuhkan.

Teknologi informasi Senayan Library Management System atau SLiMS di Perpustakaan UIN STS Jambi saat ini sudah bisa digunakan untuk melakukan penelusuran sumber-sumber informasi atau OPAC. OPAC merupakan salah satu dari fitur aplikasi SLiMS yang dapat digunakan untuk mempercepat menemukan informasi yang dibutuhkan oleh pemustaka berupa katalog koleksi perpustakaan dengan menggunakan kata kunci berupa judul buku, pengarang, subjek, dan lain sebagainya.

Hal ini terlihat dari adanya komputer yang terpajang di depan pintu masuk ruang sirkulasi. Berdasarkan observasi yang penulis lakukan dapat disimpulkan bahwa Senayan Library Management System (SLiMS) pada Perpustakaan UIN STS Jambi digunakan untuk melakukan penelusuran informasi dengan menggunakan OPAC yang terpasang di dalam komputer yang berada di depan pintu masuk ruang sirkulasi perpustakaan.

2. Hambatan Pemanfaatan Teknologi Informasi Senayan Library Management System (SLiMS) untuk Mendukung Sistem Pelayanan Informasi pada Perpustakaan UIN Sulthan Thaha Saifuddin Jambi

Di Perpustakaan UIN STS Jambi saat ini telah terpasang teknologi informasi SLiMS yang bertujuan untuk membantu dan mempercepat kerja pustakawan dan para pengelola perpustakaan dalam memberikan layanan informasi kepada pemustaka.Namun untuk mendukung sistem palayanan 
informasi di PerpustakaanUIN STS Jambi, SLiMS (Senayan Library Management System) ini belum bisa berjalan seperti yang diharapkan sebagai aplikasi yang dapat sangat membantu kegiatan di dalam perpustakaan.

Untuk mendukung sistem pelayanan informasi, SLiMS ini belum bisa menjalankan fungsinya secara maksimal. Seperti yang telah disebutkan sebelumnya, Perpustakaan UIN STS Jambi sudah pernah menggunakan SLiMS ini untuk kegiatan peminjaman dan pengembalian secara elektronis, namun tidak bertahan lama karena mengalami banyak hambatan.

Pemanfaatan SLiMS di Perpustakaan UIN STS Jambi ini terkendala oleh beberapa hal:

a. Fasilitas/Sarana dan Prasarana

1) Jaringan dan Listrik

2) Komputer dan Fasilitas lain

Mengenai fasilitas yang kurang ini, terlihat dari hanya ada 1 unit komputer yang terpajang di luar samping pintu masuk ruangan sirkulasi yang seharusnya digunakan untuk sarana temu balik informasinya (OPAC).Namun Komputer ini kadang hidup dan kadang juga mati. Jika komputer ini mati pemustaka yang ingin mencari buku, akhirnya datang menemui staf atau karyawan di ruangan sirkulasi dan menggunakan komputer staf atau pengelola tersebut dan ada juga yang langsung mencari koleksi yang dibutuhkan itu ke rak-rak koleksi.

b. Sumber Daya Manusia (SDM)

Di samping ada fasilitas atau sarana dan prasarana, ada juga yang sangat berperan di dalam mencapai suatu tujuan dalam pengaplikasian SLiMS yakni sumber daya manusia, karena perangkat sumber daya manusialah yang akan merencanakan, melaksanakan, mengendalikan, dan mengevaluasi serta menindaklanjuti suatu program otomasi perpustakaan. Untuk hal ini perpustakaan membutuhkan sumber daya manusia yang berkualitas agar bisa memainkan peranannya sebaik mungkin.

Sumber daya manusia perpustakaan adalah petugas perpustakaan yang menjalankan sistem komputer dan yang bertanggung jawab untuk 
memelihara sistem komputer yang sudah ada, serta pengecekan aplikasi apakah sudah sesuai dengan kebutuhan.Sumber daya manusia perpustakaan merupakan motor penggerak sebuah perpustakaan. Maju mundurnya sebuah perpustakaan itu terletak dari kualitas sumber daya manusianya.

Pada saat pelaksanaan penginputan data-data koleksi, terjadi beberapa kendala seperti kurang memahami isi-isi koleksi dalam bahasa asing yaitu Bahasa Arab dan Bahasa Inggris. Selain itu juga ada beberapa staf atau pengelola perpustakaan yang tidak bisa menentukan subjek untuk keyword dari koleksi tersebut sehingga menghambat dalam proses penginputan datadatanya.

c. Dana

Dana atau finansial adalah suatu yang fundamental sekali dan sering menjadi alasan terhadap terlaksana atau tidaknya dalam setiap kegiatan. Untuk melakukan kegiatan di perpustakaan tidak menutup kemungkinan adanya biaya yang dibutuhkan atau dana, baik itu untuk keperluan fasilitasnya atau juga untuk yang lain.

Dari informasi yang penulis peroleh di Perpustakaan UIN STS Jambi, penulis membuat asumsi bahwa dana yang dimiliki atau yang diterima oleh perpustakaan untuk melengkapi fasilitas dan kebutuhan akan teknologi informasi dalam belumlah mencukupi atau masih minim sehingga banyak fasilitas atau kegiatan yang tidak bisa terlaksana.

Jadi berdasarkan hal tersebut, hambatan pemanfaatan teknologi informasi Senayan Library Management System (SLiMS) untuk mendukung sistem pelayanan informasi pada Perpustakaan UIN STS Jambi adalah, fasilitas/sarana dan prasarana yang masih minim dan tidak maksimal dalam mendukung pekerjaan Perpustakaan, Dan sumber daya manusia yang masih harus ditingkatkan lagi keahlian dan profesionalismenya dalam pekerjaan serta dana yang masih harus ditingkatkan demi kelancaran setiap usaha dan kegiatan perpustakaan. 


\section{Strategi Pemanfaatan Teknologi Informasi Senayan Library} Management System (SLiMS) di Perpustakaan UIN Sulthan Thaha Saifuddin Jambi

\section{a. Fasilitas/Sarana dan Prasarana}

Menurut Undang-Undang Perpustakaan Nomor 43 Tahun 2007, setiap penyelenggara perpustakaan menyediakan sarana dan prasarana sesuai dengan standar nasional perpustakaan. Sarana dan prasarana dimanfaatkan dan dikembangkan sesuai dengan kemajuan teknologi informasi dan komunikasi. Untuk meningkatkan kuantitas dan kualitas fasilitas di Perpustakaan UIN STS Jambi dalam hal pengembangan aplikasi teknologi informasi aplikasi SLiMS untuk mendukung sistem pelayanan informasi, maka solusi atau strategi yang dapat dilakukan Perpustakaan UIN STS Jambi yaitu:

1) Mengajukan Permohonan Pengadaan kepada Lembaga Induk sesuia kebutuhan

2) Berupaya mensiasati atau menyisipkan jika ada kelebihan dana dari setiap kegiatan perpustakaan yang dilaksanakan

3) Menjaga dan memelihara fasilitas yang telah ada

\section{b. Sumber Daya Manusia (SDM)}

Selain dari fasilitas, ada juga sumber daya manusia.Sumber daya manusia di perpustakaan merupakan salah satu faktor yang penting.Oleh karena itu mesti dikembangkan sesuai dengan perkembangan dan kamajuan ilmu pengetahuan dan teknologi. Peningkatan kualitas SDM di perpustakaan harus memiliki perencanaan yang terarah.

Dalam meningkatkan kualitas kinerja pengelola perpustakaan bisa dengan mengikuti pelatihan kepustakawanan, menghadiri seminar tentang perpustakaan dan IT, atau mengikuti workshop-workshop yang diadakan oleh lembaga-lembaga terkait, seperti perpustakaan nasional. Dan hal yang terpenting ialah dalam perekrutan Pustakawan selanjutnya harusnya mengutamakan Lulusan Sarjana Ilmu Perpustakaan. 


\section{c. Dana}

Mengenai dana, yang menjadi momok dalam setiap instansi dalam melakukan pekerjaan memang harus menjadi suatu hal sangat prioritas. Dalam hal pemenuhan kebutuhan dana di perpustakaan UIN STS Jambi maka beberapa hal perlu dilakukan adalah:

1) Mengajukan permohonan dana kepada rektorat agar dana atau anggaran ini dapat dinaikkan.

2) Menggunakan dana yang tersedia untuk kegiatan yang lebih prioritas dahulu.

3) Menggunakan dana sesuai dengan kebutuhan dari kegiatan.

4) Melakukan kerjasama dengan berbagai pihak yang mempunyai kaitan dengan pendidikan dan perpustakaan

\section{E. PENUTUP}

1. Pemanfaatan teknologi informasi Senayan Library Management System (SLiMS) untuk mendukung sistem pelayanan informasi pada Perpustakaan UIN Sulthan Thaha Saifuddin Jambi saat ini belum bisa menjalankan fungsinya secara maksimal. SLiMS pernah dimanfaatkan untuk pelayanan sirkulasi yang meliputi peminjaman dan pengembalian koleksi. Teknologi informasi SLiMS di Perpustakaan UIN STS Jambi saat ini dimanfaatkan untuk kegiatan penginputan data dan penelusuran informasi dengan menggunakan OPAC yang terpasang di dalam komputer yang berada di depan pintu masuk ruang sirkulasi perpustakaan. Sedangkan kegiatan layanan peminjaman dan pengembalian masih dilakukan secara manual yaitu dengan menggunakan stempel.

2. Hambatan pemanfaatan teknologi informasi Senayan Library Management System (SLiMS) untuk mendukung sistem pelayanan informasi pada Perpustakaan UIN STS Jambi adalah, fasilitas/sarana dan prasarana yang belum mendukung, sumber daya manusia dan dana.

3. Strategi yang dilakukan untuk mengatasi hambatan dalam pemanfaatan teknologi informasi Senayan Library Management System (SLiMS) untuk mendukung sistem pelayanan informasi pada Perpustakaan UIN STS 
Jambi yaitu melakukan dengan pengajuan permohonan ke Rektorat untuk mengadakan fasilitas, meminta tambahan sumber daya manusia dan meminta tambahan dana. 


\section{DAFTAR PUSTAKA}

Abdulkadir,TerraCh.Triwahyuni. Pengenalan Teknologi Informasi. (Yogyakarta: Andi, 2005)

Agus Mulyanto. Sistem Informasi: Konsep dan Aplikasi. (Yogyakarta: Pustaka Pelajar, 2009)

Arif Surachman. Layanan Perpustakaan Berbasis Teknologi Informasi. diakses pada 25 Juli 2017

Putu Laxman Pendit. Perpustakaan Digital A Sampai Z. (Jakarta: Citra Karya Karsa Mandiri, 2008)

Romi Satria Wahono. (2006, September 27). Teknologi Informasi untuk Perpustakaan Digital dan Sistem Automasi Perpustakaan.Ilmu computer.com. Diakses pada tanggal 25 Juli 2017

Sulistyo Basuki. Pengantar Ilmu Perpustakaan. (Jakarta: Gramedia Pustaka Utama, 1993)

Wahyu Supriyanto. Teknologi Informasi Perpustakaan. (Yogyakarta: Kanisius, 2008)

Yaya Suhendar. Pedoman Katalogisasi: Cara mudah membuat katalog perpustakaan. (Jakarta: Kencana, 2010) 